\title{
Kajian Gejala Penyearahan Optik pada Metamaterial Chiral
}

\author{
Juliasih Partini ${ }^{1}$, Kamsul Abraha ${ }^{1}$, Arief Hermanto ${ }^{1}$, \\ Satoshi Tomita ${ }^{2}$, Matsui Takahiro ${ }^{2}$ \\ ${ }^{1}$ Jurusan Fisika FMIPA UGM, Sekip Utara, Yogyakarta, Indonesia \\ ${ }^{2}$ Quantum Material Science Laboratory, NAIST, Jepang \\ Email: juliasih@ugm.ac.id
}

Received 30-05-2014, Revised 11-07-2014, Accepted 22-08-2014, Published 31-10-2014

\begin{abstract}
Chiral metamaterial is a new breakthrough in the fabrication of a metamaterial because of the capability of providing different refractive index values for each circular polarization angle. This provides opportunities to obtain negative refractive index values, without the necessity to have simultaneously negative values for both permittivity and permeability. This study investigated the optical rectification, which is the phenomenon of second order non-linear optics in the chiral metamaterial. This relates to the testing of the new designs of square structure chiral metamaterial. Optical rectification is often used to 'rectify' femtoseconds laser from the realm of visible light into the terahertz domain. Nonlinear response of metamaterial was observed by terahertz emission spectroscopy. The results showed that the obtained terahertz signal is proportional to the square of the laser power used. This suggests that in the incoherent optical rectification, there is a mixture of optical rectification with the second harmonic wave generation. Development of square-structured chiral metamaterials is expected to be an alternative source of material due to the lack of non-linear material that can be used in the terahertz domain.
\end{abstract}

Keywords : Optical Rectification, Second order nonlinear optical, chiral metamaterials

\section{ABSTRAK}

Metamaterial Chiral merupakan terobosan baru dalam fabrikasi metamaterial karena kemampuan memberikan nilai indeks bias yang berbeda untuk setiap sudut polarisasi circularnya. Hal ini memberikan peluang diperolehnya nilai indeks bias negatif, tanpa keharusan memiliki nilai permitivitas yang permeabilitas yang bernilai negatif secara serentak. Penelitian ini menyelidiki penyearahan optik yang merupakan gejala optika non linear orde dua pada metamaterial chiral tersebut. Hal ini berkaitan dengan pengujian desain baru metamaterial chiral struktur persegi. Penyearahan optik seringkali digunakan untuk 'menyearahkan' laser femtodetik dari ranah cahaya tampak menjadi ranah terahertz. Uji tanggap non linear dilakukan dengan menggunakan spektroskopi emisi terahertz. Hasil penelitian menunjukkan bahwa sinyal terahertz yang diperoleh sebanding dengan pangkat dua kekuatan laser yang digunakan. Hal ini menunjukkan bahwa dalam penyearahan optik inkoheren, terdapat percampuran antara gejala penyearahan optik dengan pembangkitan gelombang harmonik kedua. Pengembangan metamaterial chiral struktur persegi ini diharapkan mampu menjadi alternatif di tengah masih minimnya sumber bahan non linear yang bisa dipergunakan dalam ranah terahertz.

Kata kunci: Penyearahan Optik, Optika Non Linear Orde Dua, Metamaterial Chiral 


\section{PENDAHULUAN}

Tanggap non linear pada suatu material menjadi salah satu gejala yang menarik dalam penelitian karena masih sangat minimnya sumber bahan non linear yang bisa dipergunakan dalam ranah terahertz ${ }^{[1]}$. Ranah frekuensi terahertz pada spektrum gelombang elektromagnetik merupakan ranah frekuensi yang berada di antara domain gelombang frekuensi tinggi (microwave) dengan domain frekuensi infra merah jauh (far infrared). Ranah frekuensi ini banyak digunakan dalam penelitian di bidang deteksi, sensor, maupun pencitraan biomedis ${ }^{[2]}$. Perkembangan terbaru penggunaan sumber gelombang Terahertz membuka kesempatan untuk memunculkan efek non linear pada material-material baru, seperti semikonduktor ${ }^{[3]}$, sumur kuantum ${ }^{[4]}$, ferroelectric ${ }^{[5]}$, maupun metamaterial ${ }^{[6]}$. Ketaklinearan instrinsik yang ditimbulkan melalui rapat polarisasi maupun rapat magnetisasi non linear orde dua meliputi pembangkitan cahaya harmonik kedua (second harmonic generation), pembangkitan medan frekuensi jumlah (sum frequency generation), pembangkitan cahaya frekuensi selisih (different frequency generation), penguatan parametrik (parametric amplification) maupun penyearahan optik (optical rectification).

Metamaterial menjadi bahan yang potensial untuk dikembangkan dalam studi non linear karena cahaya dapat dibatasi dalam skala panjang gelombang sehingga dapat diperoleh gelombang dengan intensitas yang tinggi. Hal ini akan memungkinkan peningkatan sensitivitas pada bahan ${ }^{[7]}$. Struktur metamaterial baru yang disebut sebagai metamaterial struktur chiral menjadi terobosan dalam fabrikasi metamaterial ${ }^{[8]}$. Metamaterial struktur chiral lebih sederhana dalam fabrikasi, tanpa keharusan melibatkan dua elemen struktur yang digabung, tetapi mampu memberikan nilai indeks bias berbeda untuk setiap sudut polarisasi circularnya. Penelitian ini menyelidiki gejala penyearahan optik yang merupakan gejala optika nonlinear orde dua pada struktur metamaterial chiral persegi. Hasil yang diperoleh Tomita menjadi dasar dilakukannya penelitian ini ${ }^{[9]}$.

\section{METODE}

Metamaterial merupakan material buatan dengan indeks bias negatif, yang berarti memiliki permitivitas elektrik dan permeabilitas magnetik bernilai negatif secara simultan. Indeks bias negatif menjadi salah suatu fenomena yang menarik untuk dikaji dan mendapat perhatian yang cukup luas. Tidak hanya berkaitan dengan cahaya memiliki arah yang 'berbeda' saat mengenai metamaterial, tetapi juga berbagai pemanfaatan dari metamaterial tersebut, misalnya untuk lensa sempurna, sensor biomedis, ataupun menjadi jubah tidak Nampak ${ }^{[10]}$. Dalam metamaterial, kita mengganti setiap atom penyusun material dengan suatu struktur buatan, sehingga memungkinkan material buatan tersebut memiliki nilai permitivitas ataupun nilai permeabilitas negatif. Dalam menggantikan peran atom tersebut, struktur buatan ini tentu saja harus memiliki ukuran yang lebih kecil dibanding dengan panjang gelombang elektromagnetik yang digunakan.

Munculnya struktur metamaterial baru yang disebut sebagai metamaterial struktur chiral membawa perubahan yang signifikan dalam penelitian metamaterial. Adanya sifat instrinsik asimetri pada chiral memberikan lintas kopling antara medan listrik dan medan magnet pada metamaterial chiral. Struktur ini menjawab kesulitan peneliti dalam mengembangkan metamaterial selain metamaterial konvensional yang menuntut adanya dua struktur yang sangat berbeda karakteristiknya dengan frekuensi resonansi yang sama. 
Istilah chiral digunakan untuk menjelaskan suatu obyek yang tidak mungkin sama persis dengan obyek semula ketika dikenakan pencerminan. Kata chiral ini sendiri berasal dari bahasa Yunani yang berarti tangan, yang menjadi contoh paling bagus untuk menjelaskan obyek chiral tersebut. Tangan kanan tidak akan pernah sama persis dengan tangan kiri, bagaimanapun mengubah orientasi pencerminannya ${ }^{[11]}$. Hal yang sangat kontras bila kita menggunakan obyek achiral (non chiral), dimana dengan menggunakan rotasi yang sesuai akan diperoleh keadaan yang sama dengan awalnya. Adanya sifat instrinsik asimetri pada chiral inilah yang memberikan lintas kopling antara medan listrik dan medan magnet pada frekuensi resonansinya. Lintas kopling medan ini relatif rendah pada material chiral alami. Dengan demikian metamaterial chiral dapat digunakan untuk mendapatkan sifat chiral yang kuat karena desain pada skala panjang gelombangnya.

Material chiral dapat memberikan indeks bias yang berbeda untuk tiap polarisasinya. Relasi konstitusi yang menghubungkan antar medan dalam material chiral diberikan dalam persamaan $^{[12]}$

$$
\left(\begin{array}{l}
D \\
B
\end{array}\right)=\left(\begin{array}{cc}
\varepsilon_{0} \varepsilon & i \kappa / c \\
-i \kappa / c & \mu_{0} \mu
\end{array}\right)\left(\begin{array}{l}
E \\
H
\end{array}\right)
$$

dengan $D$ adalah pergeseran elektrik, $E$ adalah medan listrik, $B$ adalah medan magnet, $H$ adalah kuat medan magnet, $\mu_{0}$ dan $\varepsilon_{0}$ adalah permeabilitas dan permitivitas vakum, $\mu$ dan $\varepsilon$ adalah permeabilitas dan permitivitas bahan chiral, $c$ adalah kecepatan cahaya, serta $\kappa$ adalah konstanta chiral yang menunjukkan kopling antara medan listrik dan medan magnet yang ada pada struktur chiral.

Indeks bias negatif pada struktur chiral tidak harus dibentuk dengan nilai permitivitas dan permeabilitas negatif pada frekuenesi resonansi yang sama. Indeks bias pada masing-masing gelombang terpolarisasi circular putaran kanan $\left(n_{+}\right)$dan putaran kiri $\left(n_{-}\right)$akan dihubungkan oleh kontanta chiral $\kappa$ dalam persamaan berikut ${ }^{[13]}$

$$
n_{ \pm}=\sqrt{\varepsilon \mu} \pm \kappa
$$

Dari persamaan (2) nampak bila indeks bias negatif dapat diperoleh dengan nilai $\kappa$ yang relatif besar. Gelombang terpolarisasi circular pada material chiral akan mengalami perubahan koefisien transmisi pada frekuensi resonansinya. Hal inilah yang memberikan kemampuan sebagai polarizer circular pada struktur chiral.

Telah dilakukan fabrikasi metamaterial chiral menggunakan Focused Ion Beam di Quantum Material Science Laboratory, Nara Institute of Science and Technology (NAIST), Jepang serta pengukuran tanggap non linear sampel menggunakan Spektroskopi Emisi Terahertz yang dilakukan di Osaka University, Jepang.

Design baru yang dibuat dalam penelitian ini berupa pola persegi dengan kedalaman yang berbeda. Dibuat dua macam sampel, yakni sampel dengan fabrikasi dalam arah putaran searah jarum jam dan dengan arah berlawanan arah jarum jam. Arah putaran yang berbeda ini akan menentukan kemiringan yang berbeda pada kedalaman pola tersebut. Ukuran struktur chiral persegi tersebut adalah panjang $1,2 \mu \mathrm{m}$, lebar $0,3 \mu \mathrm{m}$ dan kedalaman $0,3 \mu \mathrm{m}$, seperti yang terlihat pada gambar 1 berikut. Dengan berdasar pola tersebut, dilakukan fabrikasi menggunakan Focused Ion Beam sehingga diperoleh 2 macam sampel, yakni 
- Sampel 1: 300 pola dengan putaran searah jarum jam

- Sampel 2 : 300 pola dengan putaran berlawanan arah jarum jam

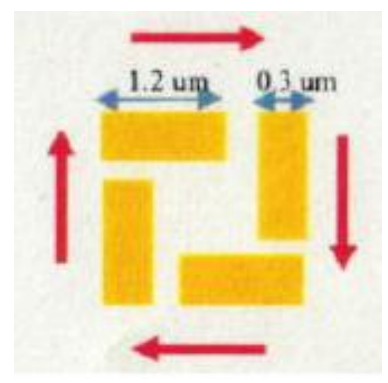

(a)

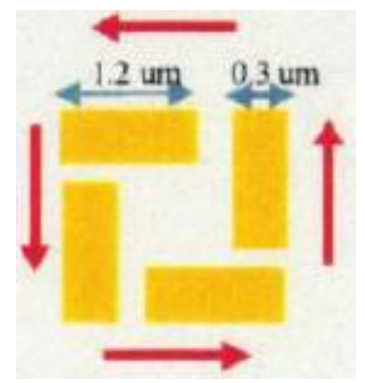

(b)

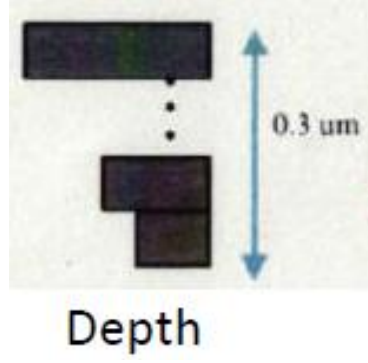

(c)

Gambar 1. (color online) Pola Desain Metamaterial Chiral dengan arah putaran (a) searah jarum jam (b) berlawanan arah jarum jam (c) kedalaman pola sampel

Dilakukan pengukuran tanggap non linear pada sampel yang telah berhasil dibuat, dengan menggunakan Spektroskopi Emisi Terahertz. Pengukuran sinyal terahertz menggunakan laser 100 fs dengan panjang gelombang sentral $800 \mathrm{~nm}$. Gambar sistem spektroskopi emisi terahertz dan skema seperti yang terlihat pada gambar 2 berikut ini.

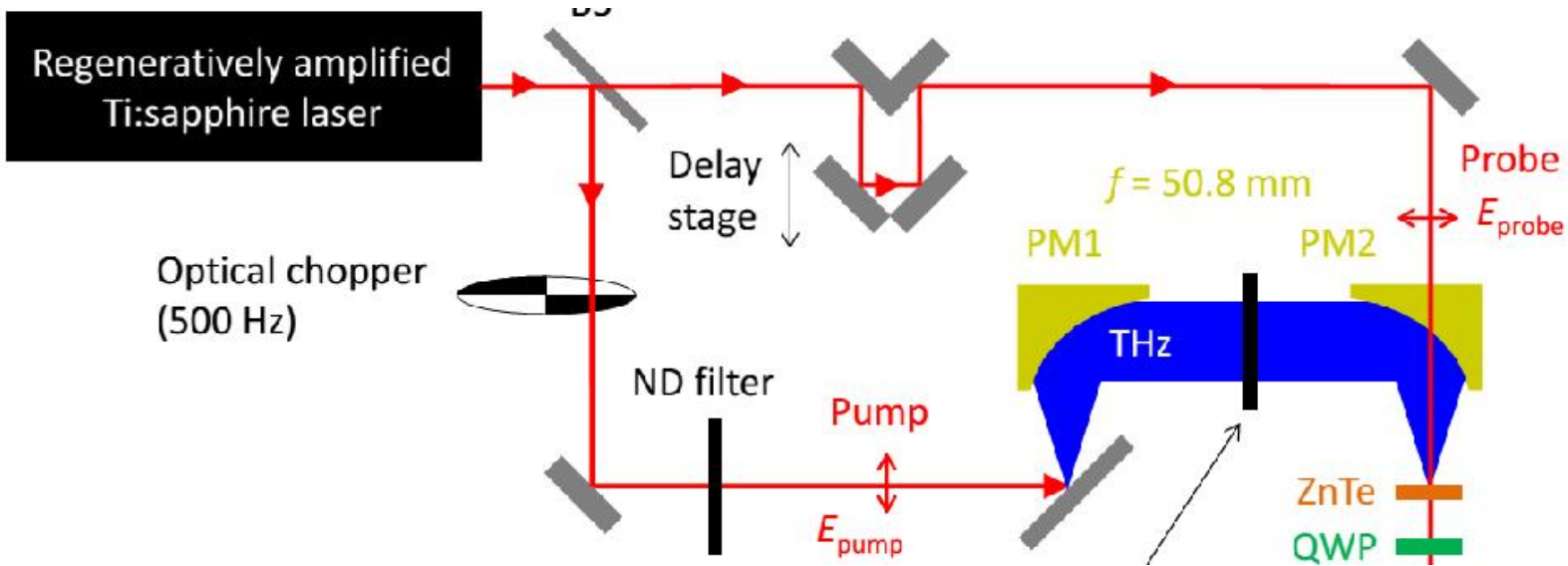

Gambar 2. (color online) Skema Spektroskopi Emisi Terahertz

\section{HASIL DAN PEMBAHASAN}

Hasil eksperimen tersaji dalam Gambar 3 berupa sinyal terahertz yang berhasil diperoleh, dengan menggunakan sampel 1 dan sampel 2. Dari hasil tersebut terlihat bahwa perbedaan pola chiral yang digunakan (arah putaran sampel) tidak mempengaruhi sinyal terahertz yang diperoleh.

Dengan menggunakan Fourier Transform dapat diperoleh spektrum frekuensi, yang menunjukkan sinyal terahertz diemisikan pada frekuensi $2 \mathrm{THz}$. 


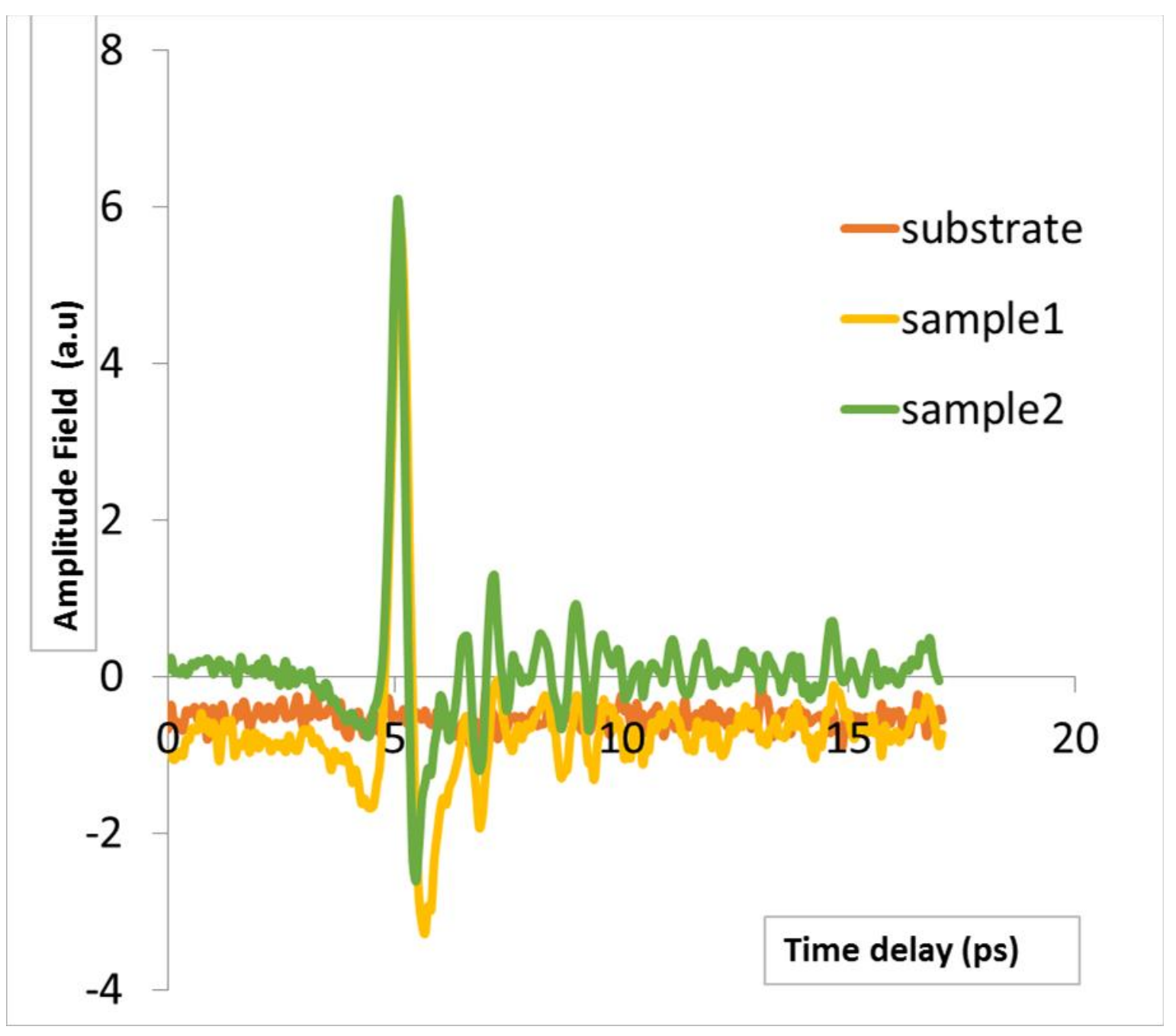

Gambar 3. (color online) Spektrum Sinyal Terahertz fungsi waktu.

Dengan melakukan variasi pada power laser pemompa, diperoleh ketergantungan sinyal emisi terahertz terhadap power yang digunakan. Fitting data digunakan untuk menyajikan pendekatan analitik yang sesuai dengan gejala penyearahan optik yang terjadi pada sampel tersebut, seperti yang disajikan di Gambar 4. 


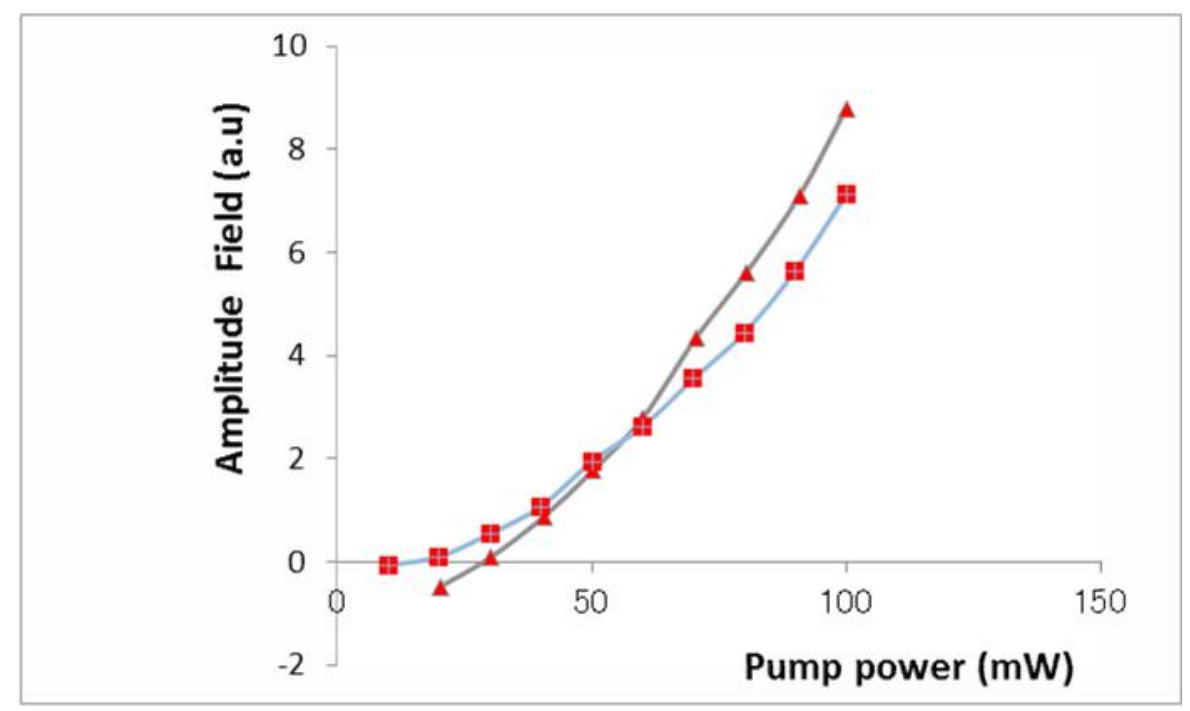

Gambar 4. (color online) Grafik ketergantungan Input laser-power dengan sinyal terahertz pada sampel 1 dan sampel 2

Hasil fitting data menunjukkan bahwa sinyal terahertz yang diperoleh sebanding dengan pangkat dua input power laser yang digunakan. Hal ini sesuai dengan pendekatan analitik pada proses penyerahan optik yang terjadi pada sampel tersebut. Pada penyearahan optik inkoheren, terdapat mixing antara gejala penyearahan optik dengan pembangkitan gelombang harmonik kedua pada sampel.

\section{KESIMPULAN}

Secara eksperimen telah berhasil diperoleh sinyal emisi terahertz pada metamaterial chiral. Sinyal terahertz yang diperoleh sebanding dengan pangkat dua kekuatan laser, yang menunjukkan adanya proses penyearahan optik pada sampel metamaterial chiral.

\section{DAFTAR PUSTAKA}

1 Liu, H., Li, G. X., Li, K. F., Chen, S. M., Zhu, S. N., Chan, C. T., dan Cheah, K. W., 2011, Linear and nonlinear Fano resonance on two dimensional magnetic metamaterials, Physical Review B, 84, pp. 235437.

2 Sigh, R., Plum, E., Zhang, W., dan Zheludev, N., 2010, Highly tunable optical activity in planar achiral terahertz metamaterials, Optics Express, Volume 18, Number 13, pp. 13425 - 13430.

3 Fan, K., Hwang, H.Y., Liu, M., Strikwerda, A.C., Sternbach, A., Zhang, J., Zhao, X., Zhang, X., Nelson, K.A., dan Averitt, R.D., 2012, Nonlinear terahertz metamaterials via field-enhanced carrier dynamics in GaAs, arXiv:1208.1538.

4 Hirori, H., Nagai, M., dan Tanaka, K., 2010, Excitonic interactions with intense terahertz pulses in ZnSe/ZnMgSSe multiple quantum wells, Phys. Rev. B, 81, pp. 081305.

5 Katayama, I., Aoki, H., Takeda, J., Shimosato, H., Ashida, M., Kinjo, R., Kawayam, I., Tonouchi, M., Nagai, M., dan Tanaka, K., 2012, Ferroelectric soft mode in a SrTiO3 thin film impulsively driven to the anharmonic regime using intense picosecond terahertz pulses Phys. Rev. Lett. 108, pp. 097401. 
6 Wang, B., Jiangfeng, Zhou, Thomas, Koschny, Maria, Kafesaki, dan Costas, Soukoulis, 2009, Chiral metamaterials: simulations and experiments, J. Opt. A: Pure Appl. Opt. 11, pp.114003

7 Savinov, V., Fedotov, V. A., Anlage, S. M., Groot, P. A. J., dan Zheludev, N., 2012, Modulating sub-THz radiation with current in superconducting metamaterial, Phys. Rev. Lett. 109, pp. 243904

8 Pendry, J.B, 2004, A Chiral Route to Negative Refraction, Science 306, pp. 1353 1355.

9 Tomita, S., Kosaka, Y., Yanagi, H., dan Sawada, K., 2013, Chiral meta interface : Polarity reversal of ellipticity through double layers consisting of transparent chiral and absorptive achiral media, Phy. Rev. B 87, 041404 (R).

10 Smith, D. R., Pendry, J. B., dan Wiltshire, M. C. K., 2004, Metamaterials and negative refractive index Science, 305, pp. 788-792.

11 Wang, B., Zhou, J., Koschny, T., dan Soukoulis, C. M., 2009, Nonplanar Chiral Metamaterials with Negative Index, Appl. Phys. Lett., 94, pp. 151112.

12 Xiong, X., Sun, W.H., Bao, Y. J., Wang, M., Peng, R. W., Sun, C., Lu, X., Shao, J., Li, Z. F., dan Ming, N. B., 2010, Phys. Rev. B: Condens. Matter, 81, 075119.

13 Gamel, J.K., Thiel, M., Rill, S., Decker, M., Bade, K., Saile, V., Freyman, G., Linden, S., Wegener, M., 2009, Science, 325, 1513. 